\title{
Fabrication of pneumatic gear changer
}

\author{
S. Vijay Kumar ${ }^{1}$, P. Nithesh Reddy ${ }^{2,}$ P. Masoom basha ${ }^{3}$ \\ ${ }^{1}$ (Assistant Professor/Mechanical Engineering, KSRM College of Engineering/JNTU Anantapur, India) \\ ${ }^{2,3}$ (UG Scholars/Mechanical Engineering, KSRM College of Engineering/JNTU Anantapur, India)
}

\begin{abstract}
In this study, a gear shifting mechanism was designed and applied to make the shifting process faster and less destructible for the driver. The new device must be reliable, has a small dimensions, low construction and maintenance cost. This paper aims to improve gear shifting process using devices as: a manual four speed gear box, two pneumatic double acting cylinders, Programmable Logic Controller (PLC), an electrical motor, limit switches, push buttons, bulbs, a table (holder) and power supply. According to suggested gear_ shifting method the control unit chooses optimum gear shifting ratio for an automobile without operating it manually (using relays). Using this method leaves to the driver the excitement of choosing the shifting moment.
\end{abstract}

Keywords: Control unit (relays) - programmable, pneumatic cylinders, Solenoid valves, gear box, gear shifting mechanism, proximity sensor.

\section{Introduction}

At present due to the extended difficulties in manual operations, the technology has shifted from manual to automatic; few of them include ABS system, active steering system e.t.c., in order to increase passenger safety and comfort. Increasing demands on performance, quality and cost are the main challenge for today's automotive industry, in an environment where movement, component and every assembly operation must be immediately and automatically recorded, checked and documented for maximum efficiency. One of the automatic applications includes pneumatic gear changer. This study describes in detail in an understandable way to how to convert the traditional manually gear shifting mechanism by using microcontroller (control unitrelays).

A method of controlling a gear change of an automobile, said automobile comprising an internal combustion engine; an automatic transmission connected to an output rotation shaft of said engine so as to transmit the rotational output of said engine to drive wheels of said automobile through any selected one of a plurality of gear ratios; a load device selectively connectable to said output rotation shaft of said engine via selectively-connecting means; and means for generating a gear change control signal for selecting one of said gear ratios of said automatic transmission in accordance with one of operational conditions of said automobile and said engine said method comprising the steps of controlling said selectively-connecting means when said gear change signal-generating means generates the control signal for shifting up the gear in said automatic transmission, in such a manner that said selectively-connecting means connects said load device to said output rotation shaft of said engine.

For some drivers, the gear shifting can cause some confusing at driving especially at critical situations. A crowded road on a hill or a sudden detour makes a lot of tension on the driver. One of the difficulties in this situation is to choose right reduction ratio and engaging it at the right time. This design helps the driver to increase his focusing on the road. Also reduces the time needed to engage the required reduction ratio, which increases the vehicles' response.

\section{Objective}

The main objective of this system is to minimize the human errors in operating the gears with the help of automatic technology. Other objectives include optimum gear ratios, reducing wear and tear of the gears, shifting the gear effectively, optimum performance of the gear box, optimum force exerted by the cylinders to move the shifting levers (pedals).

\section{Model Components}

1) A manual 4- speed gear box

2) Pneumatic cylinders

3) Programmable Logic Controller (PLC) - Micro controller

4) Directional Control Valves (DCV)

5) An electric motor (to simulate a combustion engine rotation)

6) Transformer 
7) 12 Volt DC power supply

8) Proximity sensor

9) Liquid Crystal Display

10) Relays

11) Solenoid Valve

\subsection{Model Components}

\section{Manual 4- speed gear box:}

Manual gear box is a synchronizer type with helical gears. It has one input shaft and one output shaft. It has three shifting arms; one for first and second speeds, the second one for the third and fourth speeds, third one for the neutral as shown in (Fig.1). There are three connecting rods for each arm. Every connecting rod connects its shifting arm with a common shifting lever as shown in (Fig.2). The common arm is 80 mm length with ability of sliding and axial motions. The axial motion is $35 \mathrm{~mm}$ forwards and $35 \mathrm{~mm}$ backwards $(35 \mathrm{~mm} 8.35 \mathrm{~mm})$. The sliding motion is $15 \mathrm{~mm}$ to the left and $15 \mathrm{~mm}$ to the right $\left(15 \mathrm{~mm}^{2} 15 \mathrm{~mm} \div\right)$. The arm is connected from the top with the front and rear pistons rod.
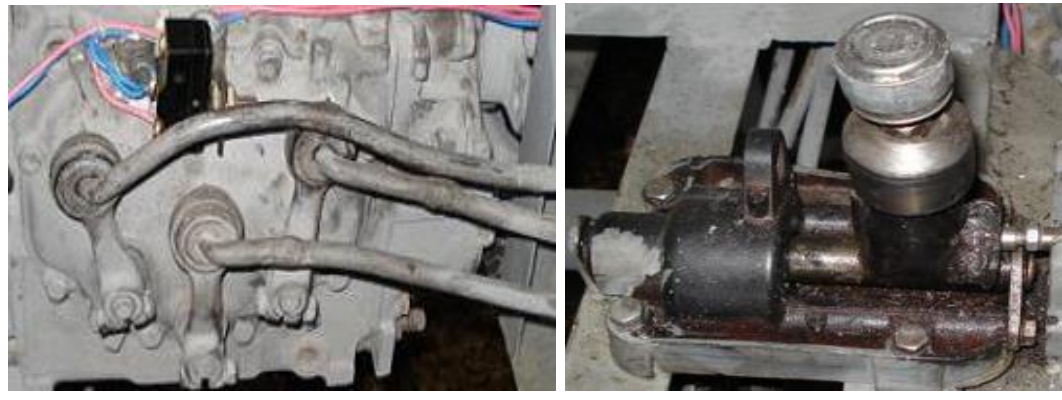

Fig. 1: Gearbox shifting arms

Fig. 2: Gearbox common shifting lever

At the end of the gearbox input shaft there is a bearing. The outer side of the shaft is fixed in the bearing and the inner side is attached with the gearbox input shaft as shown in Fig. 3

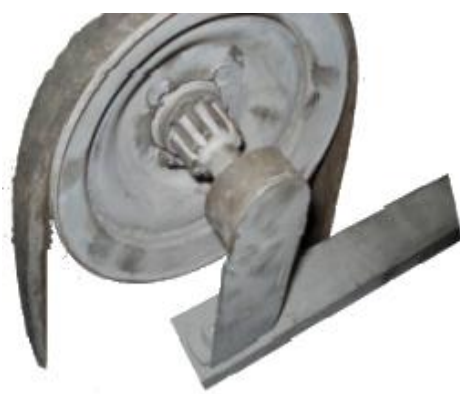

Fig. 3: Bearing

\section{Pneumatic Cylinders:}

Pneumatic cylinders (sometimes known as air cylinders) are mechanical devices which use the power of compressed gas to produce a force in a reciprocating linear motion.

It consists of two openings one on the top and another on its side below, when a compressed air is passes through the valve the piston present inside the pneumatic cylinder gets energized and ejects the piston head out. The pressure used in this pneumatic cylinder should be 2 bar, but due to large openings and leakage of the air from the cylinder the pressure can be increased to 4-5 bar.

Generally we prefer pneumatic cylinder than fluid cylinder as pneumatic cylinder has no fluid drippings and it will not affect he surroundings. As with the categorization pneumatic cylinders can be divided into 2 types

- $\quad$ Single acting cylinder (sac)

- Double acting cylinder(dac)

Single-acting cylinders:

Single-acting cylinders (SAC) use the pressure imparted by compressed air to create a driving force in one direction (usually out), and a spring to return to the "home" position. More often than not, this type of cylinder has limited extension due to the space the compressed spring takes up. Another downside to SACs is 
that part of the force produced by the cylinder is lost as it tries to push against the spring. Fig. 4 shows the schematic diagram of single acting cylinder.

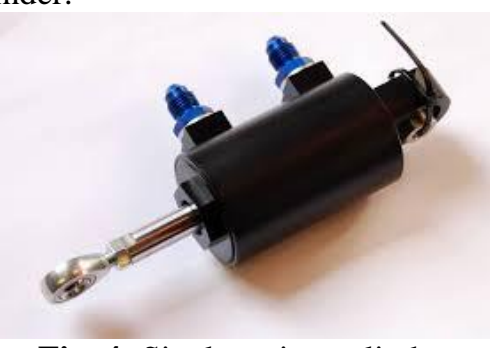

\section{Double-acting cylinders:}

Fig. 4: Single acting cylinder

Double-acting cylinders (DAC) use the force of air to move in both extract and retract strokes. They have two ports to allow air in, one for outstroke and one for in stroke. Stroke length for this design is not limited; however, the piston rod is more vulnerable to buckling and bending. Additional calculations should be performed as well. The schematic diagram of double acting cylinder is shown in Fig. 5.

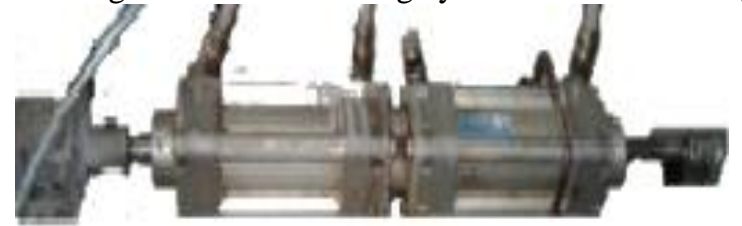

Fig. 5: Double acting cylinder

\section{Microcontroller:}

A microcontroller (sometimes abbreviated $\boldsymbol{\mu C}, \mathbf{u C}$ or $\mathbf{M C U}$ ) is a small computer on a single integrated circuit containing a processor core, memory, and programmable input/output peripherals. Program memory in the form of NOR flash or OTP ROM is also often included on chip, as well as a typically small amount of RAM. Microcontrollers are designed for embedded applications, in contrast to the microprocessors used in personal computers or other general purpose applications. In this document the type of microcontroller incorporated is AT89C52. AT89C52 is an 8-bit microcontroller and belongs to Atmel's 8051 family. AT89C52 has $8 \mathrm{~KB}$ of Flash programmable and erasable read only memory (PEROM) and 256 bytes of RAM. AT89C52 has an endurance of 1000 Write/Erase cycles which means that it can be erased and programmed to a maximum of 1000 times. The Fig. 6.1 shows the schematic diagram of AT89C52.

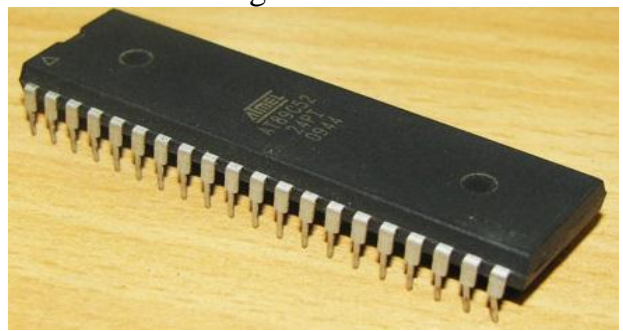

Fig. 6.1. AT89C52

Though very slight difference between the features of AT89C51 and AT89C52, they are very similar in their pin configurations* and operations. The differences between AT89C51 and AT89C52 have been tabulated in Table.1.

Table.1: Difference between AT89C51 and AT89C52

\begin{tabular}{|c|c|c|}
\hline Microcontroller & AT89C51 & AT89C52 \\
\hline RAM & 256 Bytes & 128 Bytes \\
\hline Flash & $8 \mathrm{~KB}$ & KB \\
\hline Number of timers/counters & $3(16-$ bit each) & 6 \\
\hline Number of interrupt sources & 8 & (16 each) \\
\hline
\end{tabular}

The pin configuration of AT89C52 is exactly similar to that of AT89C51 except that the first two pins, $\mathrm{P} 1.0$ and P1.1 are multiplexed to correspond to Timer2 operations as given in the following table. 2

Table.2: Pin configuration for AT89C51 \& AT89C52

\begin{tabular}{|c|c|c|}
\hline Existing & Alternate & Function \\
\hline P 1.0 & T2 & Timer/counter 2 External count input \\
\hline P 1.1 & T2 EX & Timer/counter 2 Trigger input \\
\hline
\end{tabular}


The following Fig. 7 shows the pin diagram for AT89C52:

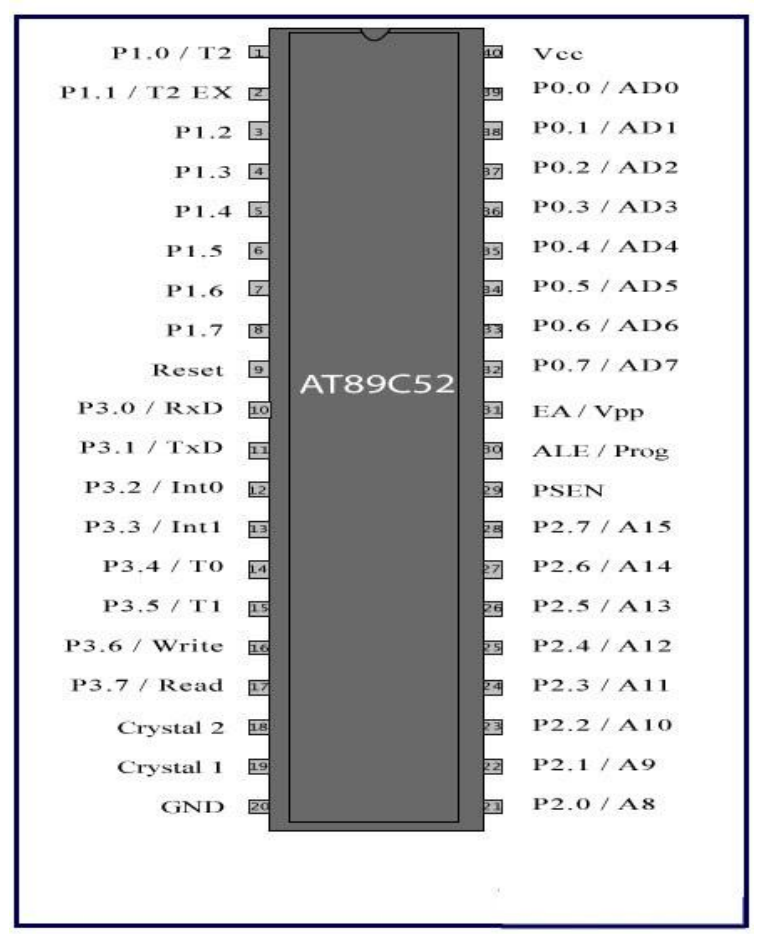

Fig.7: Pin diagram

The following Table. 3 shows the pin description

\begin{tabular}{|c|c|c|c|c|}
\hline Pin No & \multicolumn{3}{|c|}{ Function } & Name \\
\hline 1 & \multicolumn{3}{|c|}{ External count input to Timer/Counter 2, clock-out } & $\mathrm{P}_{1.0}$ \\
\hline 2 & \multicolumn{3}{|c|}{ Timer/Counter 2 capture/reload trigger and direction control } & $\mathrm{P}_{1.1}$ \\
\hline 3 & \multirow{6}{*}{\multicolumn{3}{|c|}{8 bit input/output port $\left(\mathrm{P}_{1}\right)$ pins }} & $\mathrm{P}_{1} .2$ \\
\hline 4 & & & & $\mathrm{P}_{1} .3$ \\
\hline 5 & & & & $\mathrm{P}_{1} .4$ \\
\hline 6 & & & & $\mathrm{P}_{1} .5$ \\
\hline 7 & & & & $\mathrm{P}_{1} .6$ \\
\hline 8 & & & & $\mathrm{P}_{1} .7$ \\
\hline 9 & \multicolumn{3}{|c|}{ Reset pin; Active high } & Reset \\
\hline 10 & Input (receiver) for serial communication & $\mathrm{RxD}$ & \multirow{8}{*}{$\begin{array}{c}8 \text { bit input/output port }\left(\mathrm{P}_{3}\right) \\
\text { pins }\end{array}$} & $\mathrm{P}_{3.0}$ \\
\hline 11 & Output (transmitter) for serial communication & TxD & & $\mathrm{P}_{3} .1$ \\
\hline 12 & External interrupt 1 & Int0 & & $\mathrm{P}_{3} .2$ \\
\hline 13 & External interrupt 2 & Int1 & & $\mathrm{P}_{3} .3$ \\
\hline 14 & Timer1 external input & $\mathrm{T}_{0}$ & & $\mathrm{P}_{3} .4$ \\
\hline 15 & Timer2 external input & $\mathrm{T}_{1}$ & & $\mathrm{P}_{3} .5$ \\
\hline 16 & Write to external data memory & Write & & $\mathrm{P}_{3} .6$ \\
\hline 17 & Read from external data memory & Read & & $\mathrm{P}_{3} .7$ \\
\hline 18 & \multirow{2}{*}{\multicolumn{3}{|c|}{ Quartz crystal oscillator (up to $24 \mathrm{MHz}$ ) }} & Crystal 2 \\
\hline 19 & & & & Crystal 1 \\
\hline 20 & \multirow{9}{*}{\multicolumn{3}{|c|}{$\begin{array}{l}\qquad \text { bit input/output port }\left(\mathrm{P}_{2}\right) \text { pins } \\
\text { High-order address bits when interfacing with external memory }\end{array}$}} & Ground \\
\hline 21 & & & & $\mathrm{P}_{2.0 / \mathrm{A}_{8}}$ \\
\hline 22 & & & & $\mathrm{P}_{2} .1 / \mathrm{A}_{9}$ \\
\hline 23 & & & & $\mathrm{P}_{2.2 / \mathrm{A}_{10}}$ \\
\hline 24 & & & & $\mathrm{P}_{2 .} .3 / \mathrm{A}_{11}$ \\
\hline 25 & & & & $\mathrm{P}_{2 .} .4 / \mathrm{A}_{12}$ \\
\hline 26 & & & & $\mathrm{P}_{2.5 / \mathrm{A}_{13}}$ \\
\hline 27 & & & & $\mathrm{P}_{2.6 / \mathrm{A}_{14}}$ \\
\hline 28 & & & & $\mathrm{P}_{2.7 / \mathrm{A}_{15}}$ \\
\hline 29 & \multicolumn{3}{|c|}{ Program store enable; Read from external program memory } & PSEN \\
\hline \multirow{2}{*}{30} & \multicolumn{3}{|c|}{ Address Latch Enable } & ALE \\
\hline & \multicolumn{3}{|c|}{ Program pulse input during Flash programming } & Prog \\
\hline \multirow{2}{*}{31} & \multicolumn{3}{|c|}{ External Access Enable; Vcc for internal program executions } & EA \\
\hline & \multicolumn{3}{|c|}{ Programming enable voltage; 12V (during Flash programming) } & Vpp \\
\hline 32 & \multicolumn{3}{|c|}{8 bit input/output port $\left(\mathrm{P}_{0}\right)$ pins } & $\mathrm{P}_{0.7 / \mathrm{AD}_{7}}$ \\
\hline
\end{tabular}




\begin{tabular}{|l|l|l|}
\hline 33 & \multirow{3}{*}{ Low-order address bits when interfacing with external memory } & $\mathrm{P}_{0} .6 / \mathrm{AD}_{6}$ \\
& & $\mathrm{P}_{0} .5 / \mathrm{AD}_{5}$ \\
& & $\mathrm{P}_{0} .4 / \mathrm{AD}_{4}$ \\
\cline { 3 - 3 } & & $\mathrm{P}_{0} .3 / \mathrm{AD}_{3}$ \\
\cline { 3 - 3 } & $\mathrm{P}_{0} .2 / \mathrm{AD}_{2}$ \\
\cline { 3 - 3 } & & $\mathrm{P}_{0} .1 / \mathrm{AD}_{1}$ \\
\hline 35 & & $\mathrm{P}_{0} .0 / \mathrm{AD}_{0}$ \\
\hline 37 & & $\mathrm{Vcc}$ \\
\hline 39 & &
\end{tabular}

\section{Directional Control Valves:}

The directional control valves (DCVs) are used to control the direction of the compressed air passing to the cylinders. They are compounded in one common input connected to the air pressure source and two common exhaust ports that opened to ambient. Fig. 7 illustrates the directional control valve. It has a solenoid actuator and spring.

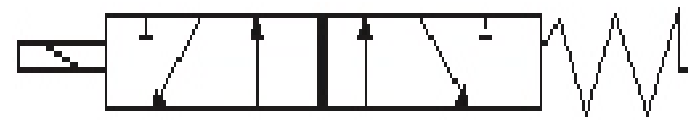

Fig. 8: Directional Control Valve

\section{Electric motor:}

In any electric motor, operation is based on simple electromagnetism. A current-carrying conductor generates a magnetic field; when this is then placed in an external magnetic field, it will experience a force proportional to the current in the conductor, and to the strength of the external magnetic field. As you are well aware of from playing with magnets as a kid, opposite (North and South) polarities attract, while like polarities (North and North, South and South) repel. The internal configuration of a DC motor is designed to harness the magnetic interaction between a current-carrying conductor and an external magnetic field to generate rotational motion. The following Fig.9 shows the schematic diagram of a DC motor.
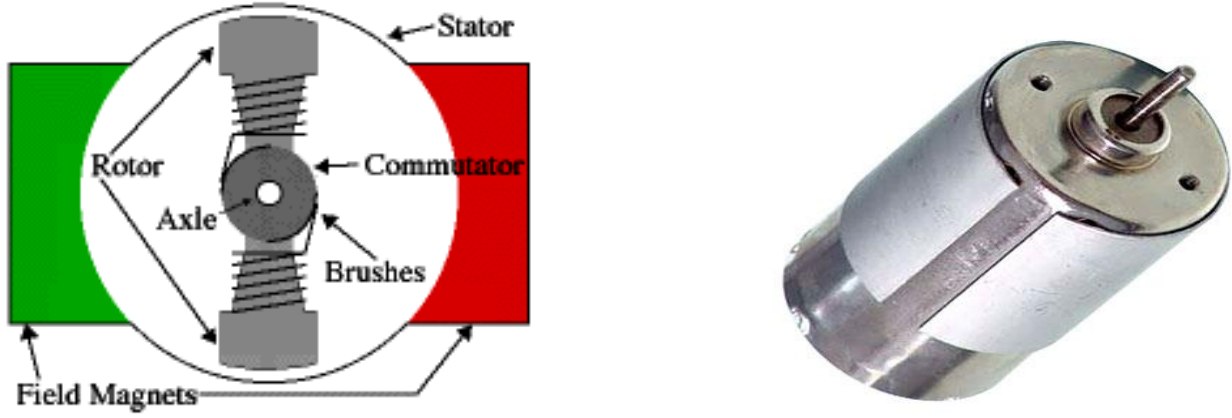

Fig.9: DC Motor

\section{Transformer:}

A Transformer is an electrical device that transfers energy between two circuits through electromagnetic induction. A transformer may be used as a safe and efficient voltage converter to change the AC voltage at its input to a higher or lower voltage at its output. A transformer most commonly consists of two windings of wire that are wound around a common core to provide tight electromagnetic coupling between the windings. The core material is often a laminated iron core. The coil that receives the electrical input energy is referred to as the primary winding; the output coil is the secondary winding.

An alternating electric current flowing through the primary winding (coil) of a transformer generates a varying electromagnetic field in its surroundings which induces a varying magnetic flux in the core of the transformer. The varying electromagnetic field in the vicinity of the secondary winding induces an electromotive force in the secondary. The Fig.10 shows the schematic representation of a transformer. 


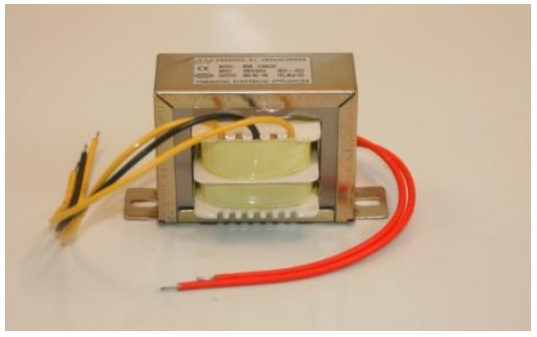

Fig.10: Transformer

\section{7. $\quad 12$ V DC power supply:}

The power supply which is incorporated in the system is Lead- acid battery $(12 \mathrm{~V})$. Rechargeable leadacid batteries are the same type used in automobiles. As with your car battery, how you use this battery has a significant impact on its lifespan. For example, if you forget to turn off your car's lights and drain the battery, a jump start might work a few times. But after a few full discharges, even a jump won't help and the battery will need to be replaced. With proper use and treatment, a lead-acid battery can last for years. Here are some recommendations for getting the longest life from the internal battery.

The following are the characteristics of battery shown in Fig.11 are rechargeable, light in weight and durable up to last power strain.

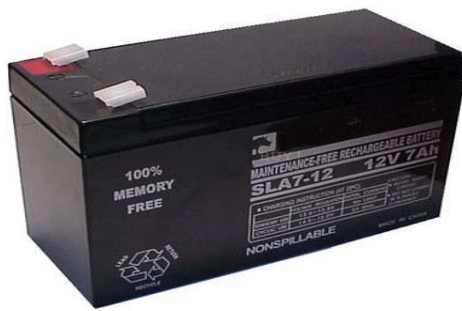

Fig.12: $12 \mathrm{~V}$ battery

\section{Proximity Sensor:}

A proximity sensor can detect metal targets approaching the sensor, a proximity sensor is a type of sensor which detects the presence of nearby objects called target without any physical contact. Depending on the type of technology used proximity sensor emits an electromagnetic or electrostatic field, or a beam of electromagnetic radiation (infrared, for instance), and looks for changes in the field or return signal when target comes closer to the face of sensor. A proximity sensor is used in many applications such as in mobile phones and for level sensing. In I phone proximity sensor is used to deactivate the touch screen when the phone comes near to the face. The following Fig. 13 shows the schematic diagram of a proximity sensor.

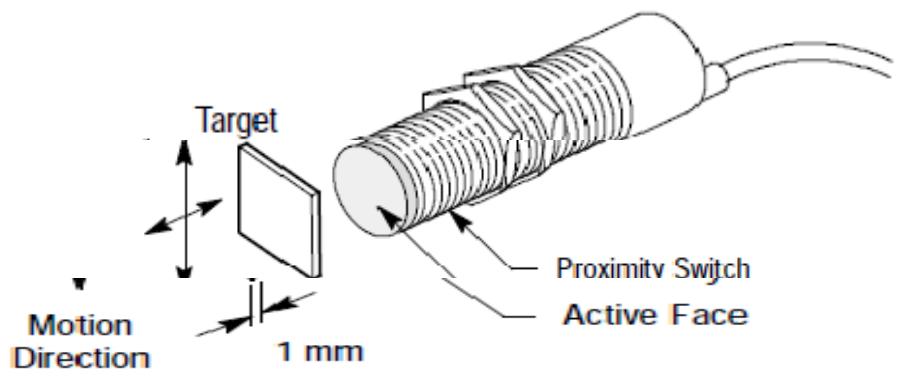

Fig.13: Sensor mounting

The principle involved in the operation of the proximity sensor is self explanatory in Fig. 14

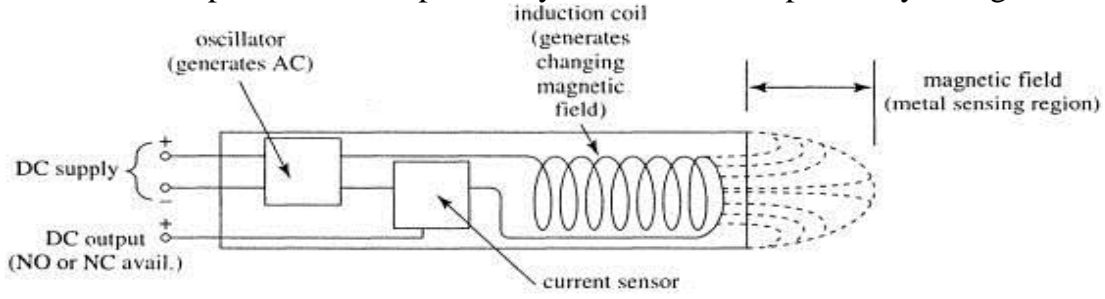

Fig.14: Principle operation of proximity sensor 


\section{Liquid Crystal Display:}

Liquid crystal display, a type of display used in digital watches and many portable computers. LCD displays utilize two sheets of polarizing material with a liquid crystal solution between them. An electric current passed through the liquid causes the crystals to align so that light cannot pass through them. Each crystal, therefore, is like a shutter, either allowing light to pass through or blocking the light. The following Fig.15 shows the representation of a LCD.

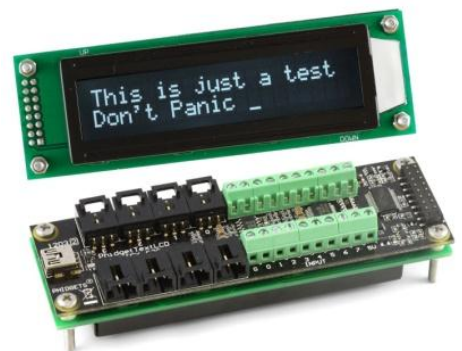

Fig.15: Liquid Crystal Display

\section{Relays:}

A relay is an electrically operated switch. Relays are used where it is necessary to control a circuit by a low power signal (with complete electrical isolation between control and controlled circuits), or where several circuits must be controlled by one signal. The following Fig.16 shows the schematic diagram of a relay.

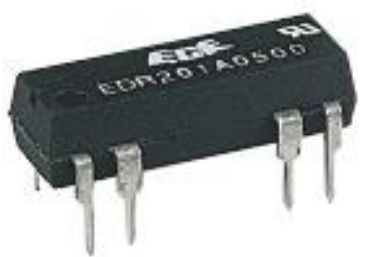

Fig. 16: Relay

When no voltage is applied to pin1, there is no current flow through the coil. No current means no magnetic field is developed, and the switch is open, when voltage is supplied to pn1, current flow through the coil creates the magnetic field to close the switch allowing continuity between 2 and 4 . The following Fig. 17 shows the operation of a relay.
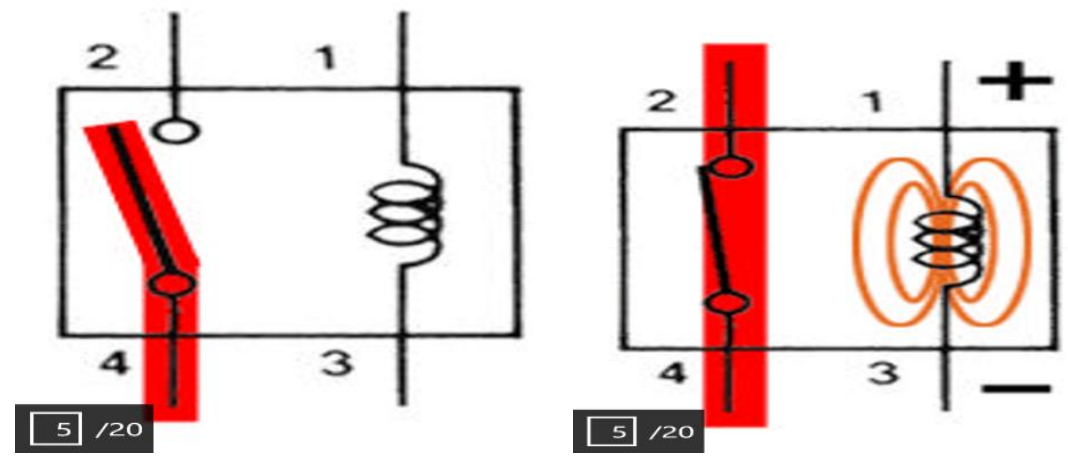

11. Solenoid Valve:

Fig. 17: Operation of a relay

Solenoid valves are electrically actuated mechanical systems that control the flow of substances like liquids and gases. Solenoid valves are commonly used on automotive transmissions. The solenoid valve uses an electric current which moves the solenoid. This pulls a piston preventing it from stopping the flow of air and fluid. The valve will need a constant flow of electrical current to remain open because when there is no current flow, the electromagnetic field scatters and the valve returns to its original position. 


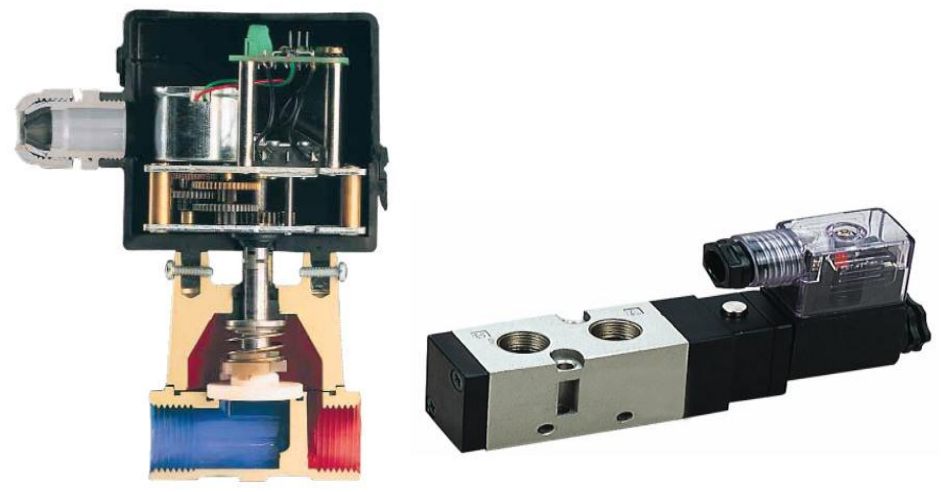

Fig.18: Solenoid Valve

IV. Working Principle:

In this construction there are two pneumatic cylinders consisting of pistons on either side of the vehicle pedal for engaging the gear. The cylinders are operated with the help of a pressurized air coming from compressor and it is controlled by a control unit (micro controller). This microcontroller (chip) is preprogrammed for working of the system. The role of two pneumatic cylinders is one for increasing the gear speed and for decreasing the gear speed. For the forward motion one cylinder is actuated \& for the reverse motion second cylinder is actuated.

\section{Construction details:}

The two solenoid valves are connected to a compressor with the help of hoses of $\emptyset 6 \mathrm{~mm}$ from which pressurized air is extracted. The solenoid valves are followed by two pneumatic cylinders with the help of air hoses. The cylinders are followed by a clutch pedal. Next to the clutch pedal gear box and a motor arrangement is present. The construction also includes a proximity sensor which senses the speed of the wheel. The precise signals are sent to the solenoid valves by the control unit through the relays. Therefore the input is speed of the wheel sensed by a sensor and the output is shifting of gear accordingly. The power to the control unit is supplied from the $12 \mathrm{~V}$ battery. On the other hand the shifting of gear can be monitored on an LCD. It also consists of DC motor, ATMEGA Development board, speed regulator (accelerator), transformer etc. The following fig. explains briefly about the construction of the pneumatic gear changer incorporated in induction motors:

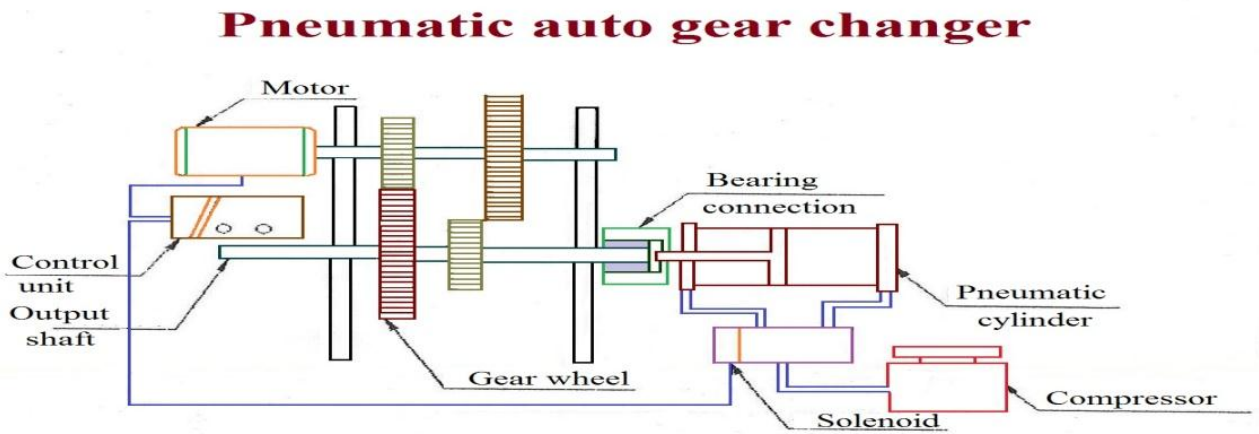

Fig.19: Block Diagram of pneumatic gear changer

\section{Working Procedure:}

The compressor sends the pressurized air to the solenoid valves through the hoses of $6 \mathrm{~mm}$ diameter whereas the solenoid valve acts as temporary storage of air and acts as passage. The air from the solenoid valves passes to the pneumatic cylinders which act as working medium for actuating cylinders. When air enter into the cylinders the pistons starts reciprocating that is extraction and retraction. The retraction is done manually by operating switches on the solenoid valves by closing the air inlet.

On the other hand the relays send the precise signals to the solenoid valves. The input for these relays is the speed of the wheel or vehicle which is sensed by sensor proximate to the wheel. The shifting of gear is done by altering the speeds by rotating the rotor in the speed regulating board i.e., accelerator in case of automobile. The following analysis shows the procedure for shifting of gears. 


\section{Logic shifting map:}

The following Fig. 20 shows the algorithm of the sequence of shifting procedure:

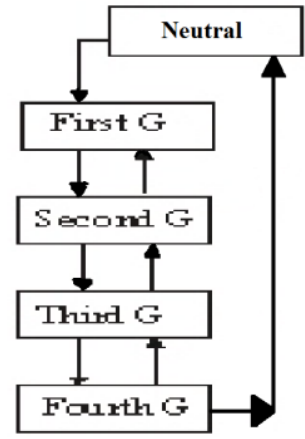

Fig. 20: Algorithm for sequence of shifting gears

From the above fig it is evident that the shifting of gears is done in a sequential manner. For example if we are driving at the first gear, we cannot engage the third gear without engaging second gear and so on. But from the fourth gear the neutral position can be achieved directly. The output signals of the control unit activate relays, needed to operate the directional valves and solenoids.. Fig. 21 shows the electrical connections.

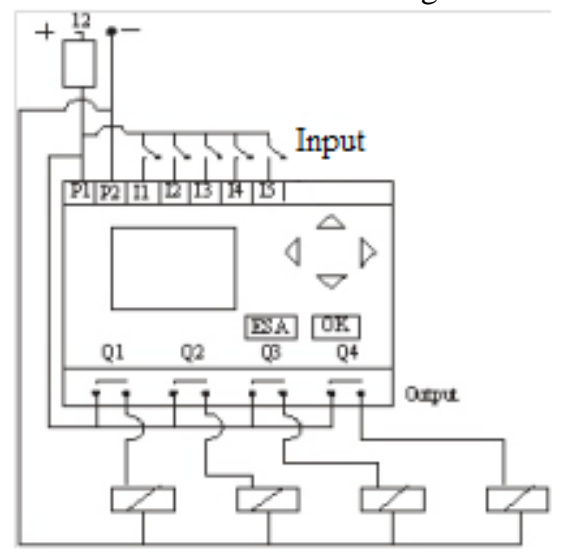

Fig.21: Electrical diagram

The following analysis shows the operational sequence of gear shifting mechanism:

\section{Neutral Position:}

In this position all controller outputs are zeros. Cylinder I is extended and cylinder II is retracted. Pressing the neutral button at any engaged gear the controller outputs will be changed to zeros. Also in any gearshift procedure the controller puts the gear in the neutral position first and then engages the desired one. The following Table. 4 shows the inputs for the neutral position.

Table.4: Inputs at neutral position

\begin{tabular}{|c|c|}
\hline Input & Description \\
\hline I1 & First gear shift \\
\hline I2 & Second gear shift \\
\hline I3 & Third gear shift \\
\hline I4 & Fourth gear shift \\
\hline I4 & Neutral position \\
\hline
\end{tabular}

The valves situation for the neutral position is shown in Table. 5:

\begin{tabular}{|c|c|c|c|}
\hline DCV & Port 2 & Port 4 & Solenoid \\
\hline A & Pressure & Exhaust & 0 \\
\hline B & Pressure & Exhaust & 0 \\
\hline C & Pressure & Exhaust & 0 \\
\hline D & Pressure & Exhaust & 0 \\
\hline
\end{tabular}




\section{First gear:}

Here, cylinder II extends while the other cylinders stay at the previous position. This action pushes the gear stick foreword. Table 6 shows the directional control valves situation for the first gear.

Table.6: DCV situation for first gear

\begin{tabular}{|c|c|c|c|}
\hline DCV & Port 2 & Port 4 & Solenoid \\
\hline A & Exhaust & Pressure & 1 \\
\hline B & Pressure & Exhaust & 0 \\
\hline C & Pressure & Exhaust & 0 \\
\hline D & Pressure & Exhaust & 0 \\
\hline
\end{tabular}

\section{Second gear:}

After controller reaches the neutral position, cylinder I is retracted. This action pulls the gear stick backward engaging the second gear. Table 7 shows the directional control valves situation for the second gear.

Table. 7: DCV situation for second gear

\begin{tabular}{|c|c|c|c|}
\hline DCV & Port 2 & Port 4 & Solenoid \\
\hline A & Pressure & Exhaust & 0 \\
\hline B & Exhaust & Pressure & 1 \\
\hline C & Pressure & Exhaust & 0 \\
\hline D & Pressure & Exhaust & 0 \\
\hline
\end{tabular}

\section{Third gear:}

After controller reaches the neutral position cylinder II will retract to allow the gear stick to engage the third gear position. Then, cylinder II extends pushing the gear stick and engages the third gear. Table 8 shows the directional control valves situation for the third gear.

Table. 8: DCV situation for third gear

\begin{tabular}{|c|c|c|c|}
\hline DCV & Port 2 & Port 4 & Solenoid \\
\hline A & Exhaust & Pressure & 1 \\
\hline B & Pressure & Exhaust & 0 \\
\hline
\end{tabular}

\section{Fourth gear:}

As in third gear, cylinder II is retracted. Then cylinder I will retract too to engage the fourth gear. Table 9 shows the directional control valves situation for the fourth gear.

Table. 9: Valve situation at fourth gear

\begin{tabular}{|c|c|c|c|}
\hline DCV & Port 2 & Port 4 & Solenoid \\
\hline A & Pressure & Exhaust & 0 \\
\hline B & Exhaust & Pressure & 1 \\
\hline C & Pressure & Exhaust & 0 \\
\hline D & Exhaust & Pressure & 1 \\
\hline
\end{tabular}

\section{Theoretical calculations:}

The calculations regarding this gear changing system are as follows:

Theoretical force required to actuate the piston $=150 \mathrm{~N}$

\section{Experimental Calculations:}

For the engaging motion cylinder

Pressure $(\mathrm{P})=4$ bar

Diameter of the piston $=32 \mathrm{~mm}$

Piston area, A:

$$
A=\frac{\pi D^{2}}{4}=\frac{\pi\left(32 \times 10^{-3}\right)^{2}}{4}=8.04 \times 10^{-4} \mathrm{~m}^{2}
$$

Connecting rod cross sectional area, a:

$$
a=\frac{\pi d^{2}}{4}=\frac{\pi\left(10 \times 10^{-3}\right)^{2}}{4}=7.85 \times 10^{-5} \mathrm{~m}^{2}
$$

Net area, $\mathrm{A}^{\prime}$ :

$$
\begin{aligned}
& A^{t}=A-a=8.04 \times 10^{-4}-7.85 \times 10^{-5} \\
& =7.25 \times 10^{-4} m^{2}
\end{aligned}
$$


The extracted force, FEX:

$$
F_{E X}=p \times A=4 \times 10^{5} \times 8.04 \times 10^{-4}=321.6 \mathrm{~N}
$$

The retracted force, FRE:

$$
F_{R E}=p \times A^{t}=4 \times 10^{5} \times 7.25 \times 10^{-4}=290 \mathrm{~N}
$$

For the sliding motion cylinder

Pressure $=4$ bar

Theoretical sliding force required $=70 \mathrm{~N}$

Piston area, A:

$$
A=\frac{\pi D^{2}}{4}=\frac{\pi\left(20 \times 10^{-1}\right)^{2}}{4}=3.14 \times 10^{-4} \mathrm{~m}^{2}
$$

Connecting rod cross sectional area, a:

$$
a=\frac{\pi d^{2}}{4}=\frac{\pi\left(8 \times 10^{-1}\right)^{2}}{4}=5.02 \times 10^{-5} \mathrm{~m}^{2}
$$

Net area, $A^{\prime}$ :

$$
\begin{aligned}
A^{t} & =A-a=3.14 \times 10^{-4}-5.02 \times 10^{-5} \\
& =2.63 \times 10^{-4} m^{2}
\end{aligned}
$$

The extracted force, FEX:

$$
F_{E X}=p \times A=4 \times 10^{5} \times 2.63 \times 10^{-4}=105.2 \mathrm{~N}
$$

The retracted force, FRE:

\begin{tabular}{|l|l|}
$\qquad F_{R E}=p \times A^{\prime}=4 \times 10^{5} \times 2.63 \times 10^{-4}=105.2 \mathrm{~N}$ \\
\hline Engaging motion cylinder & Sliding motion cylinder \\
\hline Pressure, $\mathrm{P}=4$ bar & Pressure $=4$ bar \\
\hline Diameter of piston $=32 \mathrm{~mm}$ & Diameter of piston $=20 \mathrm{~mm}$ \\
\hline Theoretical force required for engaging $=150 \mathrm{~N}$ & Theoretical force required for sliding $=70 \mathrm{~N}$ \\
\hline Extracted Force, FEX $=321.6 \mathrm{~N}$ & Extracted Force, FEX $=105.2 \mathrm{~N}$ \\
\hline Retracted Force, FRE $=290 \mathrm{~N}$ & Retracted Force, FRE $=105.2 \mathrm{~N}$ \\
\hline
\end{tabular}

\section{Conclusion:}

The project presented has involved the development and implementation of automatic transmissions for bikes. The motivation of this work is to implement this idea in clutch featured bikes with a suitable clutch control. The automatic transmission can be also used in 5 and 6 speed versions by altering few changes in the program. Therefore from the above calculations it is evident that the forces exerted by the cylinders are optimum to move the shifting levers (pedals). According to the achieved results, the suggested mechanism is realizable and workable. Using the simplest PLC and required hardware enables to convert the old traditional gear shifting mechanism to semi automatic one. The application of this mechanism leads to make the driving process easier, reduces the risk of destabilizing the car, the lap/stage time, and the chance of miss shifting.

\section{References}

[1]. Brejcha, M.F., 1993. Automatic Transmissions and Transaxles. Prentice-Hall, Englewood Cliffs, New York.

[2]. Clements-Jewery, K. and W. Jeffcoat, 1996. The PLC Workbook; Programmable Logic Controllers Made Easy. Prentice Hall.

[3]. Glielmo, L., L. Lannelli and V. Vacca, 2006. Gearshift control for automated manual transmissions. IEEE/ASME Tran. Mech., 11(1): 17-25.

[4]. Inalpolat. M. and A. Kahraman, 2008. Dynamic modelling of planetary gears of automatic transmissions. Proc. I Mech E Part D: J. Automobile Eng., 222: 229-242.

[5]. Okada, T., T. Minowa, M. Kayano, T. O chi, H. Sakamoto and H. Kuroiwa, 2002. Gear shift control technique for auto-shift manual transmission system with torque assist mechanism. JSAE Tran, 33(2): 61-66, (In Japanese).

[6]. Taguchi, Y., A. Mineno, H. Kuzuya, Y. Soga, I. Horiuchi, Y. Ueda and T. Miyazaki, 2003. Development of an automated manual transmission system based on robust design. Transm. Driveline Sys. Symp., SP- 1760: 79-85.

[7]. Yi, J., 1998. Modern Vehicle Automatic Transmission. Sichuan Technology Publishing Company, Chengdu, China, pp: 35-50. 